\title{
Effects of Subject-Case Marking on Agreement Processing: ERP evidence from Basque
}

\author{
Wing-Yee Chow ${ }^{\mathrm{a}, \mathrm{b}}$, Andrew Nevins a ${ }^{\mathrm{a}}$, Manuel Carreiras ${ }^{\mathrm{b}, \mathrm{c}, \mathrm{d}}$ \\ ${ }^{a}$ Research Department of Linguistics, Division of Psychology and Language Sciences, University \\ College London, Chandler House, 2 Wakefield Street, London WC1N 1PF, UK \\ ${ }^{\mathrm{b}}$ BCBL, Basque Center on Cognition, Brain and Language, Paseo Mikeletegi 69, 20009 \\ Donostia-San Sebastian, Spain \\ ${ }^{\mathrm{c}}$ Ikerbasque, Basque Foundation for Science, Alameda Urquijo, 36-5, Plaza Bizkaia, 48011 \\ Bilbao, Spain \\ ${ }^{\mathrm{d}}$ University of the Basque Country UPV/EHU. Campus de Leioa. Bilbao, Spain
}

Corresponding author:

Wing-Yee Chow (wingyee.chow@ucl.ac.uk)

Present address:

Chandler House, 2 Wakefield Street, London, WC1N 1PF, United Kingdom 


\begin{abstract}
Previous cross-linguistic research has found that comprehenders are immediately sensitive to various kinds of agreement violations across languages. We focused on Basque, a verb-final ergative language with both subject-verb $(\mathrm{S}-\mathrm{V})$ and object-verb $(\mathrm{O}-\mathrm{V})$ agreement. We compared the effects of S-V agreement violations on comprehenders' event-related brain potentials (ERPs) in transitive sentences (where $\mathrm{O}-\mathrm{V}$ agreement is present, and the subject is ergative) and intransitive sentences (where $\mathrm{O}-\mathrm{V}$ agreement is absent, and the subject is absolutive). We observed a P600 effect in both cases, but only violations with intransitive subjects elicited an early posterior negativity. Such a qualitative difference suggests that distinct neurocognitive mechanisms are involved in processing agreement with transitive subjects (which are marked with ergative case) vs. intransitive subjects (which bear absolutive case). Building on theoretical proposals that in languages such as Basque, true agreement occurs with absolutive subjects but not with ergative subjects, we submit that the early posterior negativity may be an electrophysiological signature for true agreement.
\end{abstract}

Keywords:

Basque, number agreement, morphosyntactic processing, early posterior negativity, P600

Highlights:

- ERP study of Basque, a morphologically rich language

- Compares ERP responses to agreement violations in transitive vs intransitive verbs

- Integrates case-marking with ERP indices of agreement processing 


\section{Introduction}

Language is full of dependencies between non-adjacent elements. One type of dependency that has been studied extensively in linguistics as well as in cognitive neuroscience is agreement, namely, the matching of features (e.g., person, gender, number) between two elements in a sentence (e.g., subject-verb, object-verb; adjective-noun; determiner-noun). Previous research has looked at different languages to examine and compare how the brain processes agreement that (i) involves different features, including number (De Vincenzi et al., 2003; Hagoort, Brown, \& Groothusen, 1993; Kutas \& Hillyard, 1983), gender (Barber \& Carreiras, 2005; Barber, Salillas, \& Carreiras, 2004; Hagoort \& Brown, 1999), person (FrenckMestre, Osterhout, McLaughlin, \& Foucart, 2008; Hinojosa, Martín-Loeches, Casado, Muñoz, \& Rubia, 2003) as well as comparisons across features (Alemán Bañón, Fiorentino, \& Gabriele, 2012; Alemán Bañón \& Rothman, 2016; Barber \& Carreiras, 2003, 2005; Hagoort, 2003; Mancini, Molinaro, Rizzi, \& Carreiras, 2011; Martín-Loeches, Nigbur, Casado, Hohlfeld, \& Sommer, 2006; Nevins, Dillon, Malhotra, \& Phillips, 2007; Silva-Pereyra \& Carreiras, 2007; Zawiszewski, Santesteban, \& Laka, 2016) and (ii) occurs between different constituents (Barber \& Carreiras, 2005; Díaz, Sebastián-Gallés, Erdocia, Mueller, \& Laka, 2011; Zawiszewski \& Friederici, 2009).

Little is known, however, about what happens when the brain has to process multiple instances of grammatical agreement within the same clause. How does the computation of different grammatical agreement relationships interact with each other? For instance, would the cognitive system's computation of subject-verb (S-V) agreement be affected when it has to compute object-verb (O-V) agreement at the same time? Furthermore, little is known about how 
grammatical case may interact with agreement processing. For example, will the computation of S-V agreement differ depending on the grammatical case of the subject?

Basque, a language spoken in the Basque country in northern Spain and southwestern France, presents a perfect testing ground for this question. Basque is a verb-final ergative language with a rich case-inflectional system (de Rijk, 2008; Hualde \& Ortiz de Urbina, 2003; Laka, 1996). As illustrated in (1) and (2), subjects of transitive verbs are marked with the ergative case $(-k)$, while direct objects of transitive verbs and subjects of unaccusative verbs like 'arrive' are absolutive and unmarked. Therefore, the subject noun phrase (NP) in a transitive sentence like (1) has ergative case, while that in an intransitive sentence such as (2) have absolutive case. ${ }^{1}$

1. ikaslea-k mutila ikusi zuen student-[Erg.sg-the] boy-[Abs.sg.the] seen 3sg.A.aux.past.3sg.E

"The student saw the boy."

2. ikaslea heldu zen student-[Abs.sg-the] arrived 3sg.A.aux.past

"The student arrived."

3. Ni-k emakume-a ikusi dut I-[Erg] woman-[Abs.sg.the] seen 3sg.A.aux.1sg.E "I have seen the woman."

\footnotetext{
${ }^{1}$ These patterns of case-marking hold generally across tenses in Basque, but notably, in progressive constructions, transitive subjects of a class of aspectual verbs are marked as absolutive (Laka, 2006). While we do not examine the way in which these constructions cause a departure from the ordinary pattern of case-marking in Basque within the present study, we return to a discussion of their potential value in future comparisons in the conclusion.
} 
In affirmative sentences, the main verb appears in a nonfinite form (a participle) after all of its arguments and is immediately followed by a finite auxiliary. ${ }^{2}$ Crucially, as illustrated in (3), Basque has multiple verb agreement, such that the finite auxiliary agrees not only with the subject NP, but also with any direct object and indirect object NP present. Therefore, the number of constituents that undergo agreement with the auxiliary in a sentence critically depends on the verb's argument structure. For intransitive verbs like 'arrive' in (2) which only takes a subject and no objects, only S-V agreement has to be computed at the auxiliary. Meanwhile, for transitive verbs like 'see' in (1) which take both an ergatively-marked subject and a direct object, both S-V and O-V agreements must be computed at the auxiliary.

Taken together, when it comes to $\mathrm{S}-\mathrm{V}$ agreement in Basque, transitive and intransitive sentences differ in two interesting ways: (i) S-V agreement has to be computed in conjunction with O-V agreement in transitive sentences but not in intransitive sentences, and (ii) subject NPs have ergative case in transitive sentences but absolutive case in intransitive sentences. Therefore, the present study will capitalize on the presence of multiple verb agreement and the case system in Basque to examine whether and how the processing of S-V agreement may differ between transitive and intransitive sentences. This study adds to the growing body of research that draws on findings from a typologically diverse set of languages to inform the cognitive neuroscience of language (e.g., Bornkessel-Schlesewsky et al., 2011), as Basque is an SOV ergative casemarking language with a rich system of agreement on the auxiliary, all of which place it in stark contrast to languages such as English.

\footnotetext{
${ }^{2}$ The finite auxiliary is fronted to the left of the arguments in negated sentences (Pablos, 2011).
} 
Before describing the details of the present experiment and predictions, we will first introduce the event-related potentials (ERPs) components that have been implicated in agreement processing. We will then review existing ERP findings on agreement processing in Basque.

ERP components implicated in agreement processing

Event-related brain potentials (ERPs) have been used extensively in the study of agreement processing. Most studies have used a violation paradigm to compare participants' ERP response to a target word that has correct vs. incorrect agreement (grammatical: "John runs"

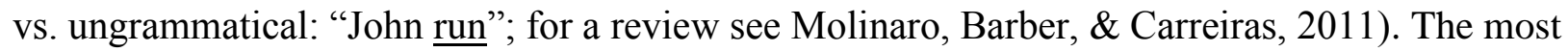
robust finding across previous studies that examined agreement processing in different languages is that agreement violations commonly elicit an increased posterior positivity starting at around 500ms after stimulus onset known as the P600 (Alemán Bañón et al., 2012; Coulson, King, \& Kutas, 1998; Hagoort \& Brown, 2000; Kolk, Chwilla, van Herten, \& Oor, 2003; Münte, Szentkuti, Wieringa, Matzke, \& Johannes, 1997; Nevins et al., 2007; Osterhout \& Mobley, 1995; Silva-Pereyra \& Carreiras, 2007). This positivity is sometimes found to be preceded by an increased negativity between $300-500 \mathrm{~ms}$ after stimulus onset. This negativity tends to have an anterior distribution and is at times found to be left-lateralised (a LAN; Caffarra \& Barber, 2015; Caffarra, Siyanova-Chanturia, Pesciarelli, Vespignani, \& Cacciari, 2015; De Vincenzi et al., 2003; Gunter, Friederici, \& Schriefers, 2000; Münte, Heinze, \& Mangun, 1993; Osterhout \& Mobley, 1995; Silva-Pereyra \& Carreiras, 2007), although in some cases it has also been found to be largest at central-posterior sites and has been considered an N400 effect instead (Barber \& 
Carreiras, 2003; Guajardo \& Wicha, 2014; Mancini et al., 2011; Zawiszewski \& Friederici, 2009; Zawiszewski et al., 2016).

Note, however, that these ERP components are not exclusively sensitive to agreement violations. They are all known to be modulated by other factors and their functional significance is still under debate to date. For instance, while some earlier accounts have taken the P600 to reflect grammatical or syntactic processing (Hagoort et al., 1993; Osterhout \& Holcomb, 1992; Osterhout \& Nicol, 1999), many have since demonstrated that the P600 is sensitive to various non-syntactic anomalies (e.g., semantic anomalies, spelling errors) and non-linguistic factors (e.g., task, proportion of trials with anomalies) and have instead taken it to reflect domaingeneral processes such as error detection and reanalysis (Coulson et al., 1998; Hahne \& Friederici, 1999; Kuperberg, 2007; van de Meerendonk, Kolk, Vissers, \& Chwilla, 2010). Further, although the P600 is typically found to have a posterior distribution (e.g., Kaan \& Swaab, 2003; Kutas \& Hillyard, 1983; Osterhout \& Mobley, 1995; van Petten \& Luka, 2012), in some cases it was found to be broadly distributed initially (around 500-750ms) and become more posterior later in time (around 750-1000ms), which has been taken to suggest that the P600 reflects two distinct stages of processing (Barber \& Carreiras, 2005; Carreiras, Salillas, \& Barber, 2004; Friederici, Mecklinger, Spencer, Steinhauer, \& Donchin, 2001; Hagoort \& Brown, 2000).

\section{Previous ERP studies on agreement processing in Basque}

To our knowledge only three previous studies have used ERPs to look at agreement processing in Basque. In the initial study, Zawiszewski and Friederici (2009) compared the effects of S-V and O-V agreement violations as participants read transitive sentences that contained a mix of person and/or number agreement violations. They found that both S-V and O- 
V agreement violations elicited a P600 effect following a centro-posterior negativity in an earlier time interval, which they took to be an N400 effect. In a subsequent study, Díaz et al. (2011) examined the effects of $\mathrm{S}-\mathrm{V}$ and $\mathrm{O}-\mathrm{V}$ number agreement violations as participants listened to transitive sentences in Basque. They found that both S-V and O-V number agreement violations elicited a P600 effect, but an early posterior negativity was found in the O-V conditions only; however, this early effect may in part be attributable to early physical differences in the auditory stimuli, as the ERP responses were measured from the onset of the auxiliary, which differed between conditions within their first syllable. More recently, Zawiszewski et al. (2016) examined participants' ERPs as they read transitive sentences in which the subject and the verb failed to agree in their (i) person feature, (ii) number feature, and (iii) person and number features. They found that all three types of S-V agreement violations elicited a posterior negativity followed by a P600 effect relative to the grammatical control.

Results from these studies revealed important similarities as well as differences in the effects of agreement violations in Basque compared to other languages. Crucially, agreement violations consistently elicit a P600 effect in Basque and other languages alike. Further, the P600 effect elicited by agreement violations is at times preceded by a negativity. However, unlike the negativity reported in previous studies which typically has a left-anterior distribution, the negativity found in these studies in Basque tends to have a centro-posterior distribution.

\section{The present study}

While previous studies have compared the effects of S-V and O-V agreement violations in Basque, to our knowledge no previous work has explored how S-V agreement may be modulated by the presence or absence of $\mathrm{O}-\mathrm{V}$ agreement. Specifically, in the present study we 
asked whether the processing of S-V agreement may differ between transitive sentences, in which O-V agreement is also present, and intransitive sentences, which have no object and therefore no $\mathrm{O}-\mathrm{V}$ agreement. In addition, as noted above, subjects in transitive and intransitive sentences also bear different grammatical cases, leading to a design that allows us to investigate the potential interaction between case and agreement processing.

In the present experiment, we only used unaccusative verbs (e.g., arrive) in intransitive sentences; we did not use unergative verbs (e.g., dance) because they have been argued to have implicit objects (Bobaljik, 1993). Meanwhile, we manipulated the number feature of the subject $\mathrm{NP}$ as well as that of the auxiliary to create grammatical vs. ungrammatical S-V number agreement. Further, in order to minimize potential interference from the object NP (c.f. plural markedness effect: Bock \& Miller, 1991; Pearlmutter, Garnsey, \& Bock, 1999), we kept all object NPs in transitive sentences singular and ensured that they always agreed with the verbs. In other words, while $\mathrm{S}-\mathrm{V}$ agreement violations were present in half of the experimental sentences, no $\mathrm{O}-\mathrm{V}$ agreement violation was ever present in the present experiment.

Based on previous findings, $\mathrm{S}-\mathrm{V}$ number agreement violations are expected to elicit a P600 effect in transitive and intransitive sentences alike. However, different hypotheses about how the processing of $\mathrm{S}-\mathrm{V}$ agreement may be affected by case and/or the presence of $\mathrm{O}-\mathrm{V}$ agreement could lead to very different predictions about how results might differ between transitive and intransitive sentences.

If the processing $\mathrm{S}-\mathrm{V}$ and $\mathrm{O}-\mathrm{V}$ agreements are completely independent from each other, then the brain's response to S-V agreement violations should not be modulated by the presence 
of $\mathrm{O}-\mathrm{V}$ agreement in transitive sentences. Under this view, the effects of $\mathrm{S}-\mathrm{V}$ agreement violations should be identical in transitive and intransitive sentences.

An alternative possibility is that the computation of $\mathrm{O}-\mathrm{V}$ agreement makes the processing of S-V agreement more difficult or delayed. Under this view, the presence of O-V agreement in transitive sentences should result in a quantitative change to the effects of S-V agreement violations, such that the ERP response to $\mathrm{S}-\mathrm{V}$ agreement violations might show a later onset and/or reduced amplitude in transitive sentences than in intransitive sentences.

Finally, if the brain engages distinct cognitive processes in processing $\mathrm{S}-\mathrm{V}$ agreement in transitive vs. intransitive sentences, then S-V agreement violations should elicit qualitatively different ERP responses in these sentences. Indeed, in proposals such as Arregi and Nevins (2012), $3^{\text {rd }}$ person ergative subjects - the kind found in transitive, but not intransitive verbs trigger a distinct type of grammatical dependency with the auxiliary from non-ergative ones. As a result, one might expect that the $\mathrm{S}-\mathrm{V}$ agreement in transitive verbs will show a different electrophysiological signature. For example, in addition to the presence or absence of an ERP effect, qualitative differences could also be found in an ERP effect's polarity (positive vs. negative) and topographic distribution.

\section{Methods}

\section{Participants}

Twenty-seven native speakers of Basque (14 female, mean age $=24.6$ years, range 19 31 years) from the Basque country in Spain participated in the current study. All participants learned Basque as their native language before the age of 4 . They were all right-handed (based 
on the Edinburgh Handedness Inventory; Oldfield, 1971), had normal or corrected-to-normal vision, and had no history of neurological disorder. Data from five additional participants were excluded due to low accuracy on the acceptability judgment task $(<70 \%)$. All participants gave informed consent and were paid 20 Euros for their participation.

\section{Materials}

The experimental stimuli were 120 pairs of simple active sentences with a SOV word order in Basque. As illustrated in Table 1, half of the sentences were transitive and the other half were intransitive with an unaccusative main verb (e.g., heldu, "arrive"). Both conditions included a range of agentive and non-agentive (e.g. psych) verbs, so as to ensure that transitivity was the factor under manipulation, as opposed to one based on thematic roles. All arguments were animate and in third person. In intransitive sentences the subject had absolutive case and was unmarked. In transitive sentences the subject was marked with ergative case $(-k)$; the object was singular, had absolutive case and was unmarked. In order to hold the linear distance between the subject and the verb constant, we introduced an adverb (e.g., berandu, "late") before the nonfinite verb (the participle) in intransitive sentences. Immediately following the participle was an inflected auxiliary (the target word) which either matched or mismatched the subject in number; following previous studies on Basque, the auxiliary was presented in isolation. In order to ensure that grammaticality is not confounded with the number feature of the subject and/or the auxiliary, both singular and plural forms of the subject were used within each item set to create two grammatical and two ungrammatical versions (singular/plural subject grammatical vs. singular/plural subject ungrammatical). The auxiliary always agreed in number and person with the object (third-person singular) in transitive sentences. Sentences were extended with one or 
more words to avoid sentence-final wrap-up effects. A full list of experimental materials along with approximate English translations can be found in the Supplementary Materials.

The experimental sentences were distributed in four presentation lists such that each participant saw exactly one version of each item. Each list contained 120 experimental sentences (30 per condition) and 120 filler sentences of similar length and structural complexity for a different study. The order of the sentences was randomized across participants.

Table 1. Experimental conditions and sample materials.

\begin{tabular}{|c|c|}
\hline Transitive & "Last summer the kid(s) saw the shark in the zoo." \\
\hline Grammatical & $\begin{array}{l}\text { Pasa den udan }\{\text { umeak / umeek }\} \text { marrazoa ikusi }\{\underline{\text { zuen/ zuten }}\} \text { zooan. } \\
\text { Last summer }\{\text { kid-[Erg.sg.the]/kid-[Erg.pl.the] }\} \text { shark-[Abs.sg] see }\{\underline{\text { 3sg.A-aux.past-3sg.E/ }} \\
\text { 3sg.A-aux.past-3pl.E }\} \text { in the zoo }\end{array}$ \\
\hline Ungrammatical & $\begin{array}{l}\text { Pasa den udan }\{\text { umeak / umeek }\} \text { marrazoa ikusi }\{\underline{\text { zuten/ zuen }}\} \text { zooan. } \\
\text { Last summer }\{\text { kid-[Erg.sg.the]/kid-[Erg.pl.the] }\} \text { shark-[Abs.sg] see }\{\underline{\text { 3sg.A-aux.past-3pl.E/ }} \\
\text { 3sg.A-aux.past -3sg.E }\} \text { in the zoo }\end{array}$ \\
\hline Intransitive & "Last month the minister(s) arrived late to all meetings." \\
\hline Grammatical & $\begin{array}{l}\text { Joan den hilabetean }\{\text { ministroa / ministroak }\} \text { berandu heldu }\{\underline{\text { zen/ ziren }}\} \text { bilera guztietara. } \\
\text { Last month }\{\text { minister-[Abs.sg-the }] / \text { minister- }[\text { Abs.pl.the }]\} \text { late arrive }\{\underline{\text { 3sg.A-aux.past/ 3pl.A- }} \\
\text { aux.past }\} \text { to all meetings }\end{array}$ \\
\hline Ungrammatical & $\begin{array}{l}\text { Joan den hilabetean }\{\text { ministroa/ ministroak }\} \text { berandu heldu }\{\underline{\text { ziren/ zen }}\} \text { bilera guztietara. } \\
\text { Last month }\{\text { minister-[Abs.sg-the }] / \text { minister- }[\text { Abs.pl.the }]\} \text { late arrive }\{\text { 3pl.A-aux.past } / \text { 3sg.A- } \\
\text { aux.past }\} \text { to all meetings }\end{array}$ \\
\hline
\end{tabular}

\section{Procedure}

Participants were comfortably seated about $100 \mathrm{~cm}$ in front of a computer screen in a testing room. Sentences were presented one word at a time in a white font on a black background at the centre of the screen. Each sentence was preceded by a fixation cross that appeared for 1000ms. Each word appeared on the screen for 360ms, followed by $320 \mathrm{~ms}$ of blank screen (i.e., $680 \mathrm{~ms} \mathrm{SOA})$. The last word of each sentence was marked with a period, followed 1000ms later by the question Esaldi ona al da? (“Is this a good sentence?"). We explained to the participants 
that to be "good" a sentence needs to be grammatical and describe something that would happen normally. Participants were instructed to read each sentence attentively, avoid eye blinks and movements during the presentation of the sentences, and respond at the end of each sentence by pressing one of two buttons. Prior to the experimental session, participants were presented with 8 practice trials with feedback to familiarize themselves with the task. The experimental session was divided into four blocks of 60 sentences each, with short pauses in between. Including set-up time, an experimental session lasted around two hours on average.

\section{EEG Recording}

EEG was recorded continuously from $27 \mathrm{AgCl}$ electrodes mounted in an elastic cap: FP1/2, F3/4, C3/4, P3/4, O1/2, F7/8, T7/8, P7/8, FC1/2, CP1/2, FC5/6, CP5/6, Fz, Cz, Pz. Four additional electrodes were placed above and below the right eye and at the outer canthus of each eye to monitor eye movements and blinks. EEG recordings were amplified and digitized online at $500 \mathrm{~Hz}$ with the BrainAmp DC@ amplifier (Brain Products $\mathrm{GmbH}$ ) and impedances were kept below $5 \mathrm{k} \Omega$. All electrodes were referenced online to the left mastoid and re-referenced to the average of both mastoids offline. Data were then filtered offline with a bandpass of $0.1-40 \mathrm{~Hz}$.

\section{ERP Data Analysis}

Event-related potentials were computed for the $1000 \mathrm{~ms}$ after the onset of the target word (the auxiliary verb) relative to a $200 \mathrm{~ms}$ pre-stimulus baseline. All epochs were evaluated individually for EOG or other artifacts. Trials contaminated by artifacts were excluded from the averaging procedure, affecting $6.6 \%$ of all experimental trials. Statistical analyses on average voltage amplitudes were conducted separately for two time windows: $250-450 \mathrm{~ms}$ for the early 
negativity and $500-800$ ms for the P600. Following Lau, Holcomb \& Kuperberg (2013), we divided 20 scalp electrodes into two levels of laterality (left vs. right) and two levels of anteriority (anterior vs. posterior), defining four quadrants: left anterior (FP1, F7, F3, FC5, FC1), right anterior (FP2, F8, F4, FC6, FC2), left posterior (CP5, CP1, P3, P7, O1) and right posterior (CP6, CP2, P4, P8, O2). We conducted repeated measures ANOVAs on time-window average ERPs in these four quadrants, fully crossing transitivity (transitive vs. intransitive) and grammaticality (grammatical vs. ungrammatical) with anteriority (anterior vs. posterior) and laterality (left vs. right). Since transitivity was manipulated between different items, we discuss effects of transitivity only when they interact with the effects of grammaticality. Significant interactions between transitivity and grammaticality were resolved by comparisons within each level of transitivity. Further, we computed standardized effect sizes (Pearson's $r$ ) and their bootstrap confidence intervals $(95 \% \mathrm{CI})$ for the contrasts between the grammatical and ungrammatical conditions in each time interval (see also Chow, Smith, Lau, \& Phillips, 2016).

Further, since half of the materials had a singular subject NP and the other half had a plural subject NP, we conducted an additional analysis to examine potential effects of the subject NP's number feature on the ERP data in each time window. We expanded on the repeated measures ANOVAs described above to include subject number feature (singular vs. plural) as an additional within-participant factor, fully crossing it with transitivity, grammaticality, anteriority and laterality.

\section{Results}

Participants had an overall accuracy of $83 \%$ in their acceptability judgements (transitivegrammatical: $82.2 \%$; transitive-ungrammatical: $71.7 \%$; intransitive-grammatical: $85.8 \%$; 
intransitive-ungrammatical: $92.1 \%$ ). Their $d$-prime scores were 1.64 and 2.76 in the transitive and intransitive conditions respectively. A paired sample t-test revealed that comprehenders were more sensitive to the grammaticality of intransitive sentences than that of transitive sentences $(t(26)=9.66, p<.001)$.

ERP data from correct and incorrect trials were analysed together. Additional analyses that looked at correct trials only revealed highly similar results and are reported in the Supplementary Materials. Figure 1 shows the grand average ERPs at the target word and the topographic distribution of the effects in the $250-450 \mathrm{~ms}$ and $500-800 \mathrm{~ms}$ intervals. Visual inspection of the data indicates that $\mathrm{S}-\mathrm{V}$ agreement violations elicited an early posterior negativity in the intransitive sentences but not in the transitive sentences. Meanwhile, a P600 effect was observed in both transitive and intransitive sentences.

Figure 1. Grand average ERPs at 9 scalp electrodes and topographic distribution of ERP effects in the $250-450 \mathrm{~ms}$ and $500-800 \mathrm{~ms}$ intervals in the transitive (left) and intransitive (right) conditions.

Transitive
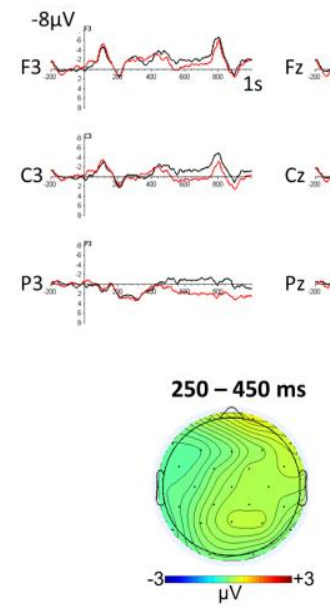

\section{Intransitive}

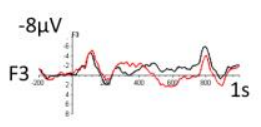

C3

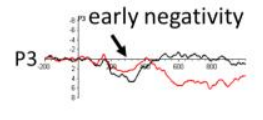

Grammatical Ungrammatical
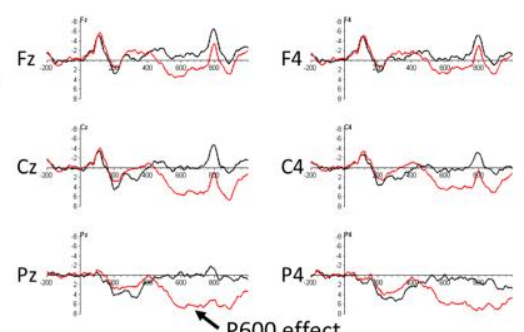
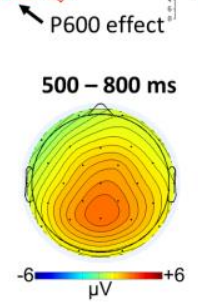
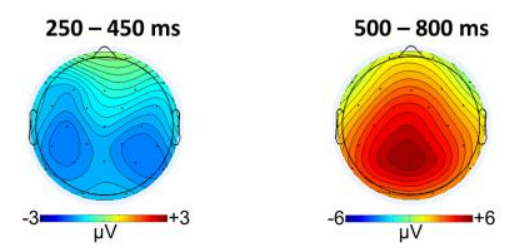
These observations were confirmed by the statistical analyses. The standardized effect size (Pearson's $r$ ) and 95\% confidence interval for the contrasts between the grammatical and ungrammatical conditions in the two time intervals are presented in Table 2.

In the $250-450 \mathrm{~ms}$ interval, the omnibus ANOVA revealed a main effect of grammaticality $(F(1,26)=4.39, p<.05)$ and a significant transitivity $\times$ grammaticality interaction $(F(1,26)=11.95, p<.01)$. Paired-sample t-tests within each level of transitivity on ERPs averaged across all scalp sites revealed a significant effect of grammaticality in the intransitive conditions $(t(26)=4.15 ; p<.001)$ but not in the transitive conditions $(t(26)=-1.18)$. Further, analyses of effect sizes across the four quadrants showed that the effect was largest at posterior sites (see Table 2). These results show that $\mathrm{S}-\mathrm{V}$ agreement violations elicited an increased posterior negativity in intransitive sentences only.

In the $500-800 \mathrm{~ms}$ interval the omnibus ANOVA revealed a main effect of grammaticality $(F(1,26)=20.03, p<.001)$, a grammaticality $\times$ anteriority interaction $(F(1,26)=$ 5.81, $p<.05)$, and a transitivity $\times$ grammaticality $\times$ laterality interaction $(F(1,26)=6.45, p<.05)$. The three-way interaction was followed up by a repeated measures ANOVA involving grammaticality and transitivity within each level of laterality, which revealed a main effect of grammaticality on both hemispheres (right: $F(1,26)=19.49, p<.001$; left: $F(1,26)=19.05, p$ $<.001)$ and a grammaticality $\times$ transitivity interaction on the left hemisphere only $(F(1,26)=$ $5.37, p<.05)$. This interaction was resolved by paired t-tests examining the effect of grammaticality on the left hemisphere within each level of transitivity, which revealed a significant grammaticality effect in both transitive $(t(1,26)=-3.28, p<.01)$ and intransitive 
$(t(1,26)=-3.99, p<.001)$ conditions. ${ }^{3}$ Along with the analyses of effect sizes across the four

quadrants (see Table 2), these results show that $\mathrm{S}-\mathrm{V}$ agreement violations elicited a late posterior

positivity (P600 effect) in both transitive and intransitive sentences, but the effect was slightly

more left-lateralised in the intransitive conditions than in the transitive conditions.

Table 2. Standardized effect size (Pearson's r) and 95\% confidence interval for the contrast between the grammatical and ungrammatical conditions in transitive and intransitive sentences in the $250-450 \mathrm{~ms}$ and $500-800 \mathrm{~ms}$ time intervals. The effect size of a contrast expressed in Pearson's $r$ is scaled to have an absolute magnitude between 0 and 1 , with the sign indicating the direction of the differences.

\begin{tabular}{|c|c|c|c|c|c|c|c|c|}
\hline \multirow[b]{3}{*}{ Quadrant } & \multicolumn{4}{|c|}{ Transitive } & \multicolumn{4}{|c|}{ Intransitive } \\
\hline & \multicolumn{2}{|c|}{$250-450 \mathrm{~ms}$} & \multicolumn{2}{|c|}{$500-800 \mathrm{~ms}$} & \multicolumn{2}{|c|}{$250-450 \mathrm{~ms}$} & \multicolumn{2}{|c|}{$500-800 \mathrm{~ms}$} \\
\hline & Effect size $r$ & $95 \% \mathrm{CI}$ & Effect size $r$ & $95 \% \mathrm{CI}$ & $\overline{\text { Effect size } r}$ & $95 \% \mathrm{CI}$ & Effect size $r$ & $95 \% \mathrm{CI}$ \\
\hline Left anterior & 0.01 & {$[-0.43,0.37]$} & 0.38 & {$[0.01,0.62]$} & -0.50 & {$[-0.71,-0.11]$} & 0.50 & {$[0.12,0.69]$} \\
\hline Right anterior & 0.25 & {$[-0.15,0.53]$} & 0.49 & {$[0.15,0.71]$} & -0.37 & {$[-0.62,0.04]$} & 0.45 & {$[0.07,0.66]$} \\
\hline Left posterior & 0.08 & {$[-0.31,0.44]$} & 0.63 & {$[0.37,0.77]$} & -0.66 & {$[-0.78,-0.37]$} & 0.70 & {$[0.55,0.80]$} \\
\hline Right posterior & 0.17 & {$[-0.22,0.50]$} & 0.63 & {$[0.34,0.78]$} & -0.62 & {$[-0.76,-0.31]$} & 0.62 & {$[0.41,0.76]$} \\
\hline
\end{tabular}

The same pattern of results were obtained in the analyses in which the subject number feature was included as an additional factor (for complete ANOVA results see Table A3 in the Supplementary Materials). Crucially, none of the effects involving the subject number feature were statistically significant (all $p \mathrm{~s}>.05){ }^{4}$

\footnotetext{
${ }^{3}$ The transitivity $\times$ grammaticality $\times$ laterality interaction was also followed up by a repeated measures ANOVA involving grammaticality and both topographic factors within each level of transitivity. Similar results were obtained. We found a main effect of grammaticality in both transitive and intransitive sentences (transitive: $F(1,26)=13.67, p$ $<.01$; intransitive: $F(1,26)=14.27, p<.001$ ), in addition to interactions between grammaticality and each topographic factor in the intransitive sentences (grammaticality $\times$ anteriority: $F(1,26)=8.15, p<.01$; grammaticality $\times$ laterality: $F(1,26)=5.19, p<.05)$.

${ }^{4}$ In order to explore potential relationships between participants' ERPs in the two time windows and their behavioural responses, we used generalised mixed effects models to predict participants' behavioural response to an acceptability judgement (yes vs. no) from their average ERP amplitude in each time window in a given trial, with the formula glmer (response amplitude $+(1 \mid$ subj $)+(1 \mid$ item), family $=$ "binomial") in the lmer R package (version 1.1-12; Bates, Maechler, Bolker \& Walker, 2015). The final models only included random by-subject and by-item intercepts in their random effect structure since models with a more
} 


\section{Discussion}

In the present study we investigated whether and how the processing of $\mathrm{S}-\mathrm{V}$ agreement may differ between transitive and intransitive sentences in Basque. We found that $\mathrm{S}-\mathrm{V}$ agreement violations consistently elicited a P600 effect in transitive and intransitive sentences alike, but this effect was preceded by a posterior negativity in the $250-450 \mathrm{~ms}$ interval only in intransitive sentences and not in transitive sentences.

The presence of a P600 effect in the current study is in line with existing findings in Basque as well as other languages. This effect had a clear posterior distribution from its onset at around 500ms and remained so throughout the rest of the epoch. This topography is typical of P600 effects reported in the broader literature (Kaan \& Swaab, 2003; Kutas \& Hillyard, 1983; Osterhout \& Mobley, 1995; van Petten \& Luka, 2012) but does not provide support for proposals which take the P600 to reflect two different phases of processing (Barber \& Carreiras, 2005; Carreiras et al., 2004; Friederici et al., 2001; Hagoort \& Brown, 2000).

Meanwhile, the observation of an early posterior negativity in the present study is also consistent with earlier findings in Basque (Zawiszewski \& Friederici, 2009; Zawiszewski et al., 2016). Given its posterior distribution, this effect is likely distinct from the left-anterior negativity (LAN) that has been reported in earlier studies in other languages and might be more similar to the N400. However, we refrain from labelling this early posterior negativity an N400 effect mainly because the timing of this effect is not typical of an N400 effect. As noted in a

complex random effect structure failed to converge. The models revealed a large effect of participants' ERPs in the $500-800 \mathrm{~ms}$ window on their behavioural response (estimate $=-0.052, \mathrm{SE}=0.006, z=-8.155, p<.001$ ). The effect of participants' ERPs in the $250-450 \mathrm{~ms}$ window was also statistically significant, albeit much smaller in magnitude (estimate $=-0.014, \mathrm{SE}=0.007, z=2.05, p=.04)$. 
review by Kutas and Federmeier (2011), the latency of the N400 response is remarkably stable, peaking at around $400 \mathrm{~ms}$ after stimulus onset across studies that vary greatly in their stimuli and tasks. However, the posterior negativity observed in the present study peaked at around $320 \mathrm{~ms}$ after target word onset, which is considerably earlier than typical N400 effects (see also the early negativity in Experiment 1 in Zawiszewski \& Friederici, 2009). Therefore, for the remainder of our discussion we will refer to this effect simply as an early posterior negativity.

Further, participants' $d$-prime scores showed that they were better at detecting S-V agreement violations in intransitive sentences compared to transitive sentences. Recall that all object NPs in transitive sentences were singular. One potential explanation for comprehenders' lower accuracy in transitive sentences is that the subject and object NPs differed in their number features half of the time. However, this was not supported by the data, as participants' average dprime score in transitive sentences was in fact lower when the subject NP was singular (1.26) than when it was plural (2.15). This suggests that their lower d-prime score in transitive sentences is not attributable to the presence of arguments with different number features in half of the sentences. Instead, this may be because the '-ak' ending, found on singular transitive subjects, is ambiguous between marking an ergative singular and an absolutive plural. However, further work is needed to understand the effects of this ambiguity, as it did not appear to have the same effect in the intransitive conditions in the present study (singular '-a': 2.50; plural '-ak': 2.79).

Returning to the main research question of the current study, we presented in the Introduction three competing hypotheses about the ways in which $\mathrm{S}-\mathrm{V}$ agreement processing may differ between transitive and intransitive sentences. The present results showed a qualitative 
difference between the brain's response to $\mathrm{S}-\mathrm{V}$ agreement violations in transitive vs. intransitive sentences, which is in line with the prediction of the third and last hypothesis positing that distinct neurocognitive mechanisms are engaged in processing S-V agreement in these sentences.

Why would S-V agreement be processed differently when it occurs in a transitive vs. intransitive sentence? The fact that we observed a qualitative, not quantitative, difference between transitive and intransitive sentences suggests that this is not due to the processor somehow simply being less sensitive to agreement violations in one than the other. Rather, we take this qualitative difference to reflect something about the nature of the agreement relation itself.

One available explanation is that agreement with ergative subjects (those that occur with transitive verbs) is different from agreement with the absolutive subject of an intransitive verb. Specifically, work such as Moravscik (1974), Woolford (2006), and Bobaljik (2008) have suggested that some languages may disallow true agreement with ergatively-case marked subjects. Arregi and Nevins (2012) suggest that the grammatical dependency between $3^{\text {rd }}$ person ergative subjects and the auxiliary verb in Basque is in fact clitic-doubling (a weak pronominal element, akin to those found with French subject clitics) and not agreement. This argument is based on a number of observations on how this marking differs from uncontroversial S-V agreement; for example, it does not vary with tense (much like pronominal clitics in French). The proposal, in essence, is that the auxiliary verb cannot actually support more than one instance of 'true' agreement. What is called 'multiple agreement' in the literature is actually true agreement with the absolutive argument (the subject of an intransitive verb, or the object of a transitive verb) plus something else. When there is a $3^{\text {rd }}$ person ergative argument (subject of a 
transitive verb), given that the main agreement relation has been 'used up' by the absolutive argument, the way to mark it on the verb is achieved by pronominal clitic doubling.

While the P600 effect found in both transitive and intransitive sentences likely reflects a more general detection of a violation, for the early posterior negativity which was observed in intransitive sentences only, we propose that it tracks violations of true agreement. Specifically, the number mismatch between absolutive subjects and the auxiliary verb elicited an early posterior negativity in intransitive sentences because it was a violation of true agreement, but no early posterior negativity was observed in transitive sentences because the grammatical dependency between $3^{\text {rd }}$ person ergative subjects and the auxiliary verb is not true agreement. These results are interesting, therefore, as they provide support for independent research in the literature suggesting that ergative 'agreement' does not always pattern the same as true agreement, and the early posterior negativity may be a neurophysiological signature for this difference.

At first blush, these results seem to be divergent from those of earlier ERP studies on Basque agreement. Specifically, the account that ergative agreement is not true agreement (and hence does not trigger an early posterior negativity when violations occur) might appear incompatible with the Zawiszewski et al.'s (2016) observation that S-V agreement violations elicited an early posterior negativity even when the subject was ergative. However, that study had a notable difference from the present one: all of the ergative subjects in question were $2^{\text {nd }}$ person. Recall that the restriction on ergatives undergoing true agreement as developed in Arregi and Nevins (2012) was based on the pattern of $3^{\text {rd }}$ person ergatives. Third person ergatives show a number of distinct properties from $1^{\text {st }}$ and $2^{\text {nd }}$ person ergatives, including a limitation in their 
ability to undergo the Ergative Displacement operation found in Basque with $3^{\text {rd }}$ person absolutive arguments, and the fact that $3^{\text {rd }}$ person pronouns are derived from demonstratives (Hualde \& Ortiz de Urbina, 2003). As a result, the S-V agreement violations with $2^{\text {nd }}$ person ergatives in Zawiszewski et al.'s (2016) study are violations of true agreement and the observed early posterior negativity is compatible with the proposal that this ERP signature tracks true agreement relations. In this light, the results of Zawiszewski and Friederici (2009) could be potentially revealing to look into further as well, as they too found an early posterior negativity effect for S-V agreement violations, although their materials included a mixture of $1^{\text {st }}, 2^{\text {nd }}$ and $3^{\text {rd }}$ person subjects. Potentially, separating out the ERP responses for $\mathrm{S}-\mathrm{V}$ agreement violations for these different persons within the materials could reveal different ERP profiles than the picture obtained by averaging them together. Finally, Díaz et al (2011) only used $3^{\text {rd }}$ person subjects and did not find an early posterior negativity to $\mathrm{S}-\mathrm{V}$ agreement violations. This is again compatible with the view that the grammatical dependency between $3^{\text {rd }}$ person ergatives and the auxiliary verb in Basque does not reflect true agreement. One additional prediction that emerges from our proposal is that $\mathrm{O}-\mathrm{V}$ agreement violations, as the single instance of true agreement, should reliably elicit an early posterior negativity in Basque. This was indeed observed by Zawiszewski and Friederici (2009).

The present results may pertain specifically to agreement processing in Basque (an SOV, ergative language), as existing research on languages with other morphosyntactic profiles present a more mixed picture in terms of when an early negativity (or a LAN) is elicited by agreement violations (Alemán Bañón \& Rothman, 2016; Molinaro, Barber, Caffarra, \& Carreiras, 2015; Molinaro et al., 2011; Tanner, 2015). Cross-linguistic comparison of structures parallel to these, as well meta-analyses of the conditions under which similar posterior negativities are elicited for 
agreement violations (Guajardo \& Wicha, 2014; Mancini et al., 2011; Shen, Staub, \& Sanders, 2013), will therefore be informative in further refining our understanding of the functional significance of this ERP component.

We have advanced the claim that the lack of an early negativity effect in the transitive conditions results from the fact that the grammatical dependency between an auxiliary and a $3^{\text {rd }}$ person ergative subject is not true agreement. We believe that these results are not attributable to the mere presence of the intervening object NP found in transitive sentences but not in intransitive sentences. Given a theoretical framework in which language processing operates over a content-addressable memory structure (e.g., Lewis, Vasishth, \& Van Dyke, 2006; McElree, Foraker, \& Dyer, 2003; Van Dyke \& McElree, 2011), the presence of an additional definite NP could give rise to more similarity-based interference in the transitive sentences than intransitive sentences (e.g., Fedorenko, Gibson, \& Rohde, 2006; Gordon, Hendrick, Johnson, \& Lee, 2006; van Dyke \& Johns, 2012). However, it is unclear how a quantitative difference in the amount of memory interference in these sentences would explain the qualitative difference we observed. Further, agreement attraction is also unlikely to explain the present results. This is because we deliberately avoided potential agreement attraction effects by using only singular object NPs in transitive sentences, as previous studies have demonstrated that only plural distractors give rise to agreement attraction effects (the plural markedness effect: Bock \& Miller, 1991; Pearlmutter et al, 1999).

One prediction of our proposal, therefore, is that the same effects should be observed even when (i) an additional NP is introduced in intransitive sentences to match the transitive sentences in terms of the level of similarity-based interference (such as by modifying the subject 
with a pre-nominal prepositional phrase, e.g., Gasteizko ministroa, meaning 'the minister from Vitoria'), or (ii) the materials have a non-canonical OSV order, where the subject appears after the object and immediately before the verb (for related work on the effects of non-canonical OSV order on agreement processing in Basque, see Santesteban, Pickering, \& Branigan, 2013).

The overall contributions of the present study have been as follows. First, we have provided further electrophysiological evidence regarding the signatures of agreement violations in Basque, adding to the recent research efforts on this typologically distinct language. Further, the observation of a qualitative difference between $\mathrm{S}-\mathrm{V}$ agreement violations in intransitives (where the subject is absolutive) and in transitives (where it is ergative) led us to integrate these results with a grammatical model in which these superficially similar agreement processes are actually distinct kinds of grammatical relations. In particular, we proposed that the early posterior negativity may be an index of true agreement. The present results underscore the importance of considering grammatical case as a factor that can influence the nature and processing of agreement.

In Basque, as in other ergative languages, transitivity and ergative case are often found hand in hand. However, there are at least three ways that argument structure can be dissociated from ergative case marking, and these can potentially be manipulated in future studies. First, ditransitive verbs like 'give' take both indirect and direct objects and are arguably 'more transitive' than transitive verbs, but under the current model they are expected to show the same $\mathrm{S}-\mathrm{V}$ agreement processing profile because the subject NP for both transitive and ditransitive verbs is marked ergative. Second, there is a small set of unaccusative verbs like 'boil' that exceptionally take ergative case marking on their single argument. As such, the present model 
would predict no early negativity in response to agreement violations with these verbs, despite the fact that there is no object NP and thus no O-V agreement to compute. Finally, as one reviewer pointed out, in progressive transitive constructions involving the aspectual verb ari in Basque, both the subject and object NPs take absolutive case. In this case, even transitive verbs are expected to elicit an early negativity in response to $\mathrm{S}-\mathrm{V}$ agreement violations. Therefore, future work can and should look at additional manipulations of argument structure in order to examine $\mathrm{S}-\mathrm{V}$ agreement violations in cases where transitivity and ergative case marking do not fully align to examine whether the early negativity is elicited specifically by true agreement (agreement with an absolutive argument) and not by the argument structure of the verb per se. The fine-grained predictions brought forward by applying the current model to a language with many morphosyntactic variables to be compared and controlled mean that there is important work still to be done on the neurolinguistics of Basque agreement.

\section{Acknowledgements}

This work is supported by PSI2015-67353-R from the Spanish Ministry of Science and Innovation and ERC-2011-ADG-295362 from the European Research Council to MC. We thank Andrea Ganchegui and Amaia Rodriguez for help with creating the materials, along with Alazne Alegre, Itzal Uranga, Larraitz López, Adalberto Varela, Itziar Basterra, David Carcedo, and Ainara Tedone for help with data collection. We also thank Nicola Molinaro, Simona Mancini

Brian Dillon, and Leticia Pablos for discussions and comments on an earlier version of the paper. 


\section{References}

Arregi, K., \& A. Nevins. (2012). Morphotactics: The Structure of Spellout in Basque Auxiliaries. Springer.

Alemán Bañón, J., Fiorentino, R., \& Gabriele, A. (2012). The processing of number and gender agreement in Spanish: An event-related potential investigation of the effects of structural distance. Brain Research, 1456, 49-63. http://doi.org/10.1016/j.brainres.2012.03.057

Alemán Bañón, J., \& Rothman, J. (2016). The role of morphological markedness in the processing of number and gender agreement in Spanish: an event-related potential investigation. Language, Cognition and Neuroscience, 31(10), 1273-1298. http://doi.org/10.1080/23273798.2016.1218032

Barber, H. A., \& Carreiras, M. (2003). Integrating gender and number information in Spanish word pairs: an ERP study. Cortex, 39(3), 465-482. http://doi.org/10.1016/S00109452(08)70259-4

Barber, H. A., \& Carreiras, M. (2005). Grammatical gender and number agreement in Spanish: an ERP comparison. Journal of Cognitive Neuroscience, 17(1), 137-153. http://doi.org/10.1162/0898929052880101

Barber, H. A., Salillas, E., \& Carreiras, M. (2004). Gender or genders agreement. In M. Carreiras \& C. Clifton (Eds.), On-line study of sentence comprehension; eye-tracking, ERP and beyond (pp. 309-328). Brighton: Psychology Press. http://doi.org/10.4324/9780203509050

Bates, D., Maechler, M., Bolker, B., \& Walker, S. (2015). Fitting linear mixed-effects models using lme4. Journal of Statistical Software, 67, 1-48.

Bobaljik, J. D. (1993). On ergativity and ergative unergatives. MIT Working Papers in Linguistics, 19, 45-88.

Bobaljik, J. D. (2008). Where's phi? Agreement as a post-syntactic operation. In D. Adger, S. Béjar, \& D. Harbour, (Eds.), Phi-Theory: Phi features across interfaces and modules (pp. 295-328). Oxford University Press.

Bock, K., \& Miller, C. A. (1991). Broken agreement. Cognitive Psychology, 23(1), 45-93. http://doi.org/10.1016/0010-0285(91)90003-7

Bornkessel-Schlesewsky, I., Kretzschmar, F., Tune, S., Wang, L., Genç, S., Philipp, M., ... Schlesewsky, M. (2011). Think globally: Cross-linguistic variation in electrophysiological activity during sentence comprehension. Brain and Language, 117(3), 133-152. http://doi.org/10.1016/j.bandl.2010.09.010 
Caffarra, S., \& Barber, H. A. (2015). Does the ending matter? The role of gender-to-ending consistency in sentence reading. Brain Research, 1605(1), 83-92.

http://doi.org/10.1016/j.brainres.2015.02.018

Caffarra, S., Siyanova-Chanturia, A., Pesciarelli, F., Vespignani, F., \& Cacciari, C. (2015). Is the noun ending a cue to grammatical gender processing? An ERP study on sentences in Italian. Psychophysiology, 52(8), 1019-1030. http://doi.org/10.1111/psyp.12429

Carreiras, M., Salillas, E., \& Barber, H. (2004). Event-related potentials elicited during parsing of ambiguous relative clauses in Spanish. Cognitive Brain Research, 20(1), 98-105. http://doi.org/10.1016/j.cogbrainres.2004.01.009

Chow, W.-Y., Smith, C., Lau, E., \& Phillips, C. (2016). A “ bag-of-arguments ” mechanism for initial verb predictions. Language, Cognition and Neuroscience, 31(5), 577-596. http://doi.org/10.1080/23273798.2015.1066832

Coulson, S., King, J. W., \& Kutas, M. (1998). Expect the Unexpected: Event-related Brain Response to Morphosyntactic Violations. Language and Cognitive Processes, 13(1), 21-58. http://doi.org/10.1080/016909698386582

de Rijk, R. (2008). Standard Basque: A progressive grammar. Cambridge, MA: MIT Press.

De Vincenzi, M., Job, R., Di Matteo, R., Angrilli, A., Penolazzi, B., Ciccarelli, L., \& Vespignani, F. (2003). Differences in the perception and time course of syntactic and semantic violations. Brain and Language, 85(2), 280-296. http://doi.org/10.1016/S0093934X(03)00055-5

Díaz, B., Sebastián-Gallés, N., Erdocia, K., Mueller, J. L., \& Laka, I. (2011). On the crosslinguistic validity of electrophysiological correlates of morphosyntactic processing: A study of case and agreement violations in Basque. Journal of Neurolinguistics, 24(3), 357373. http://doi.org/10.1016/j.jneuroling.2010.12.003

Fedorenko, E., Gibson, E., \& Rohde, D. (2006). The nature of working memory capacity in sentence comprehension: Evidence against domain-specific working memory resources. Journal of Memory and Language, 54(4), 541-553. http://doi.org/10.1016/j.jmlrijk.2005.12.006

Frenck-Mestre, C., Osterhout, L., McLaughlin, J., \& Foucart, A. (2008). The effect of phonological realization of inflectional morphology on verbal agreement in French: Evidence from ERPs. Acta Psychologica, 128(3), 528-536. http://doi.org/10.1016/j.actpsy.2007.12.007

Friederici, A. D., Mecklinger, A., Spencer, K. M., Steinhauer, K., \& Donchin, E. (2001). Syntactic parsing preferences and their on-line revisions: A spatio-temporal analysis of event-related brain potentials. Cognitive Brain Research, 11(2), 305-323. http://doi.org/10.1016/S0926-6410(00)00065-3 
Gordon, P. C., Hendrick, R., Johnson, M. L., \& Lee, Y. (2006). Similarity-based interference during language comprehension: Evidence from eye tracking during reading. Journal of Experimental Psychology. Learning, Memory, and Cognition, 32(6), 1304-1321. http://doi.org/10.1037/0278-7393.32.6.1304

Guajardo, L. F., \& Wicha, N. Y. Y. (2014). Morphosyntax can modulate the N400 component: Event related potentials to gender-marked post-nominal adjectives. NeuroImage, 91, 262272. http://doi.org/10.1016/j.neuroimage.2013.09.077

Gunter, T. C., Friederici, A. D., \& Schriefers, H. (2000). Syntactic gender and semantic expectancy: ERPs reveal early autonomy and late interaction. Journal of Cognitive Neuroscience, 12, 556-568. http://doi.org/10.1162/089892900562336

Hagoort, P. (2003). How the brain solves the binding problem for language: A neurocomputational model of syntactic processing. NeuroImage, 20(SUPPL. 1), 18-29. http://doi.org/10.1016/j.neuroimage.2003.09.013

Hagoort, P., \& Brown, C. M. (1999). Gender electrified: ERP evidence on the syntactic nature of gender processing. Journal of Psycholinguistic Research, 28(6), 715-728. http://doi.org/10.1023/A:1023277213129

Hagoort, P., \& Brown, C. M. (2000). ERP effects of listening to speech compared to reading: The P600/SPS to syntactic violations in spoken sentences and rapid serial visual presentation. Neuropsychologia, 38(11), 1531-1549. http://doi.org/10.1016/S00283932(00)00053-1

Hagoort, P., Brown, C. M., \& Groothusen, J. (1993). The Syntactic Positive Shift (SPS) as an ERP measure of Syntactic Processing. Language and Cognitive Processes, 8(4), 439-483.

Hahne, A., \& Friederici, A. D. (1999). Electrophysiological Evidence for Two Steps in Syntactic Analysis : Early Automatic and Late Controlled Processes. Journal of Cognitive Neuroscience, 11(2), 194-205.

Hinojosa, J., Martín-Loeches, M., Casado, P., Muñoz, F., \& Rubia, F. (2003). Similarities and differences between phrase structure and morphosyntactic violations in Spanish: An eventrelated potentials study. Language and Cognitive Processes, 18(2), 113-142. http://doi.org/10.1080/01690960143000489

Hualde, J. I., \& Ortiz de Urbina, J. (2003). A grammar of Basque. Berlin: Mouton de Gruyter.

Kaan, E., \& Swaab, T. Y. (2003). Repair, revision, and complexity in syntactic analysis: An electrophysiological differentiation. Journal of Cognitive Neuroscience, 15(1), 98-110. http://doi.org/10.1162/089892903321107855 
Kolk, H. H. J., Chwilla, D. J., van Herten, M., \& Oor, P. J. W. (2003). Structure and limited capacity in verbal working memory: A study with event-related potentials. Brain and Language, 85(1), 1-36. http://doi.org/10.1016/S0093-934X(02)00548-5

Kuperberg, G. R. (2007). Neural mechanisms of language comprehension: Challenges to syntax. Brain Research, 1146(1), 23-49. http://doi.org/10.1016/j.brainres.2006.12.063

Kutas, M., \& Federmeier, K. D. (2011). Thirty years and counting: finding meaning in the N400 component of the event-related brain potential (ERP). Annual Review of Psychology, 62(August), 621-47. http://doi.org/10.1146/annurev.psych.093008.131123

Kutas, M., \& Hillyard, S. A. (1983). Event-related brain potentials to grammatical errors and semantic anomalies. Memory \& Cognition, 11(5), 539-550.

http://doi.org/10.3758/BF03196991

Laka, I. (1996). A brief grammar of Euskara, the Basque language. University of the Basque Country, Office for the Vicerector for the Basque Language. Retrieved from http://www.ehu.es/grammar

Laka, Itziar. 2006. Deriving split ergativity in the progressive: The case of Basque. In A. Johns, D. Massam \& J. Ndayiragije (Eds.), Ergativity: Emerging issues (pp. 173-196). Dordrecht, Springer.

Lau, E. F., Holcomb, P. J., \& Kuperberg, G. R. (2013). Dissociating N400 effects of prediction from association in single-word contexts. Journal of Cognitive Neuroscience, 25(3), 484502. http://doi.org/10.1162/jocn_a_00328

Lewis, R. L., Vasishth, S., \& Van Dyke, J. A. (2006). Computational principles of working memory in sentence comprehension. Trends in Cognitive Sciences, 10(10), 447-454. http://doi.org/10.1016/j.tics.2006.08.007

Mancini, S., Molinaro, N., Rizzi, L., \& Carreiras, M. (2011). A person is not a number: Discourse involvement in subject-verb agreement computation. Brain Research, 1410, 6476. http://doi.org/10.1016/j.brainres.2011.06.055

Martín-Loeches, M., Nigbur, R., Casado, P., Hohlfeld, A., \& Sommer, W. (2006). Semantics prevalence over syntax during sentence processing: A brain potential study of nounadjective agreement in Spanish. Brain Research, 1093(1), 178-189.

http://doi.org/10.1016/j.brainres.2006.03.094

McElree, B., Foraker, S., \& Dyer, L. (2003). Memory structures that subserve sentence comprehension. Journal of Memory and Language, 48(1), 67-91. http://doi.org/10.1016/S0749-596X(02)00515-6 
Molinaro, N., Barber, H. A., Caffarra, S., \& Carreiras, M. (2015). On the left anterior negativity (LAN): The case of morphosyntactic agreement: A Reply to Tanner etal. Cortex, 66, 156159. http://doi.org/10.1016/j.cortex.2014.06.009

Molinaro, N., Barber, H. A., \& Carreiras, M. (2011). Grammatical agreement processing in reading: ERP findings and future directions. Cortex, 47(8), 908-930.

http://doi.org/10.1016/j.cortex.2011.02.019

Moravcsik, E. A. (1978). Agreement. In J. H. Greenberg, C. A. Ferguson \& E. A. Moravcsik (Eds.), Universals of Human Language IV: Syntax (pp. 331-374). Stanford: Stanford University Press.

Münte, T. F., Heinze, H. J., \& Mangun, G. R. (1993). Dissociation of brain activity related to syntactic and semantic aspects of language. Journal of Cognitive Neuroscience, 5(3), 33544. http://doi.org/10.1162/jocn.1993.5.3.335

Münte, T. F., Szentkuti, A., Wieringa, B. M., Matzke, M., \& Johannes, S. (1997). Human brain potentials to reading syntactic errors in sentences of different complexity. Neuroscience Letters, 235(3), 105-108. http://doi.org/10.1016/S0304-3940(97)00719-2

Nevins, A., Dillon, B. W., Malhotra, S., \& Phillips, C. (2007). The role of feature-number and feature-type in processing Hindi verb agreement violations. Brain Research, 1164(1), 8194. http://doi.org/10.1016/j.brainres.2007.05.058

Oldfield, R. C. (1971). The assessment and analysis of handedness: The Edinburgh inventory. Neuropsychologia, 9, 97-113. http://doi.org/10.1016/0028-3932(71)90067-4

Osterhout, L., \& Holcomb, P. J. (1992). Event-related brain potentials elicited by syntactic anomaly. Journal of Memory and Language, 31(6), 785-806. http://doi.org/10.1016/0749596X(92)90039-Z

Osterhout, L., \& Mobley, L. a. (1995). Event-Related Brain Potentials Elicited by Failure to Agree. Journal of Memory and Language. http://doi.org/10.1006/jmla.1995.1033

Osterhout, L., \& Nicol, J. L. (1999). On the Distinctiveness, Independence, and Time Course of the Brain Responses to Syntactic and Semantic Anomalies. Language and Cognitive Processes, 14(3), 283-317.

Pablos, L. (2011). Rich Agreement in Basque: Evidence for Pre-verbal Structure Building. In Y. Hirose, J. Packard, \& H. Yamashita (Eds.), Processing and Producing Head-Final Structures. Studies in Theoretical Psycholinguistics. (Vol. 38, pp. 3-21). Dordrecht: Springer. http://doi.org/10.1007/978-90-481-9213-7_1

Pearlmutter, N. J., Garnsey, S. M., \& Bock, K. (1999). Agreement Processes in Sentence Comprehension. Journal of Memory and Language, 41, 427-456. http://doi.org/10.1006/jmla.1999.2653 
Santesteban, M., Pickering, M. J., \& Branigan, H. P. (2013). The effects of word order on subject-verb and object-verb agreement: Evidence from Basque. Journal of Memory and Language, 68(2), 160-179. http://doi.org/10.1016/j.jml.2012.09.003

Shen, E. Y., Staub, A., \& Sanders, L. D. (2013). Event-related brain potential evidence that local nouns affect subject-verb agreement processing. Language and Cognitive Processes, 28(4), 498-524. http://doi.org/10.1080/01690965.2011.650900

Silva-Pereyra, J. F., \& Carreiras, M. (2007). An ERP study of agreement features in Spanish. Brain Research, 1185(1), 201-211. http://doi.org/10.1016/j.brainres.2007.09.029

Tanner, D. (2015). On the left anterior negativity (LAN) in electrophysiological studies of morphosyntactic agreement: A Commentary on "Grammatical agreement processing in reading: ERP findings and future directions" by Molinaro et al., 2014. Cortex, 66, 149-155. http://doi.org/10.1016/j.cortex.2014.04.007

van de Meerendonk, N., Kolk, H. H. J., Vissers, C. T. W. M., \& Chwilla, D. J. (2010). Monitoring in language perception: mild and strong conflicts elicit different ERP patterns. Journal of Cognitive Neuroscience, 22(1), 67-82. http://doi.org/10.1162/jocn.2008.21170

van Dyke, J. A., \& Johns, C. L. (2012). Memory Interference as a Determinant of Language Comprehension. Linguistics and Language Compass, 6(4), 193-211. http://doi.org/10.1002/lnc3.330

van Dyke, J. A., \& McElree, B. (2011). Cue-dependent interference in comprehension. Journal of Memory and Language, 65(3), 247-263. http://doi.org/10.1016/j.jml.2011.05.002

van Petten, C., \& Luka, B. J. (2012). Prediction during language comprehension: Benefits, costs, and ERP components. International Journal of Psychophysiology, 83(2), 176-190. http://doi.org/10.1016/j.ijpsycho.2011.09.015

Woolford, E. (2006). Case-Agreement Mismatches. In C. Boeckx (Ed.), Agreement Systems (pp. 317-339). John Benjamins Publishing.

Zawiszewski, A., \& Friederici, A. D. (2009). Processing canonical and non-canonical sentences in Basque: The case of object-verb agreement as revealed by event-related brain potentials. Brain Research, 1284, 161-179. http://doi.org/10.1016/j.brainres.2009.05.099

Zawiszewski, A., Santesteban, M., \& Laka, I. (2016). Phi-features reloaded: An ERP study on person and number agreement processing. Applied Psycholinguistics, 37, 601-626. http://doi.org/10.1017/S014271641500017X 


\section{Supplementary Materials}

Table A1. ANOVA F-values at the target word (correct trials only).

\begin{tabular}{lccc} 
& $\mathrm{df}$ & $250-450 \mathrm{~ms}$ & $500-800 \mathrm{~ms}$ \\
\hline Omnibus ANOVA & & & \\
transitivity & 1,26 & $<1$ & $3.98^{\wedge}$ \\
grammaticality & 1,26 & $4.79^{*}$ & $22.44^{* *}$ \\
transitivity $\times$ grammaticality & 1,26 & $17.86^{* *}$ & $<1$ \\
transitivity $\times$ ant & 1,26 & $<1$ & $<1$ \\
grammaticality $\times$ ant & 1,26 & $<1$ & $7.67^{*}$ \\
transitivity $\times$ lat & 1,26 & $7.9^{* *}$ & $14.02^{* *}$ \\
grammaticality $\times$ lat & 1,26 & $5.61^{*}$ & 2.49 \\
transitivity $\times$ grammaticality $\times$ ant & 1,26 & $<1$ & $4.63^{*}$ \\
transitivity $\times$ grammaticality $\times$ lat & 1,26 & $<1$ & $5.67^{*}$ \\
transitivity $\times$ ant $\times$ lat & 1,26 & $6.74^{*}$ & $5.33^{*}$ \\
grammaticality $\times$ ant $\times$ lat & 1,26 & 1 & 1.95 \\
transitivity $\times$ grammaticality $\times$ ant $\times$ lat & 1,26 & $<1$ & $<1$ \\
\hline
\end{tabular}

Topographic factors: ant $=$ anteriority; lat $=$ laterality.

$* * p<.01$

$* p<.05$

$\wedge .05<p<.1$

Table A2. Standardized effect size (Pearson's r) and 95\% confidence interval for the contrast between the grammatical and ungrammatical conditions in transitive and intransitive sentences in the $250-450 \mathrm{~ms}$ and $500-800 \mathrm{~ms}$ time intervals (correct trials only).

\begin{tabular}{|c|c|c|c|c|c|c|c|c|}
\hline \multirow[b]{3}{*}{ Quadrant } & \multicolumn{4}{|c|}{ Transitive } & \multicolumn{4}{|c|}{ Intransitive } \\
\hline & \multicolumn{2}{|c|}{$250-450 \mathrm{~ms}$} & \multicolumn{2}{|c|}{$500-800 \mathrm{~ms}$} & \multicolumn{2}{|c|}{$250-450 \mathrm{~ms}$} & \multicolumn{2}{|c|}{$500-800 \mathrm{~ms}$} \\
\hline & Effect size $r$ & $95 \% \mathrm{CI}$ & Effect size $r$ & $95 \% \mathrm{CI}$ & Effect size $r$ & $95 \% \mathrm{CI}$ & Effect size $r$ & $95 \% \mathrm{CI}$ \\
\hline Left anterior & 0.08 & {$[-0.31,0.45]$} & 0.56 & {$[0.25,0.73]$} & -0.60 & {$[-0.75,-0.33]$} & 0.48 & {$[0.11,0.70]$} \\
\hline Right anterior & 0.27 & {$[-0.10,0.58]$} & 0.64 & {$[0.35,0.80]$} & -0.51 & {$[-0.71,-0.17]$} & 0.39 & {$[0.03,0.62]$} \\
\hline Left posterior & 0.12 & {$[-0.27,0.47]$} & 0.67 & {$[0.41,0.80]$} & -0.65 & {$[-0.78,-0.38]$} & 0.72 & {$[0.60,0.81]$} \\
\hline Right posterior & 0.21 & {$[-0.22,0.54]$} & 0.71 & {$[0.47,0.82]$} & -0.62 & {$[-0.76,-0.31]$} & 0.63 & {$[0.39,0.76]$} \\
\hline
\end{tabular}


Table A3. ANOVA F-values at the target word in the additional analysis which included the number feature of the subject as an additional within-participants factor (all trials).

\begin{tabular}{|c|c|c|c|}
\hline & df & $250-450 \mathrm{~ms}$ & $500-800 \mathrm{~ms}$ \\
\hline \multicolumn{4}{|l|}{ Omnibus ANOVA } \\
\hline transitivity & 1,26 & $<1$ & $8.15^{* *}$ \\
\hline grammaticality & 1,26 & $3.85^{\wedge}$ & $21.94 * *$ \\
\hline number & 1,26 & $<1$ & $<1$ \\
\hline transitivity $\times$ grammaticality & 1,26 & $11.22^{* *}$ & $3.56^{\wedge}$ \\
\hline transitivity $\times$ number & 1,26 & 1.42 & $<1$ \\
\hline grammaticality $\times$ number & 1,26 & $<1$ & $<1$ \\
\hline transitivity $\times$ ant & 1,26 & $<1$ & $<1$ \\
\hline grammaticality $\times$ ant & 1,26 & 1.25 & $5.6^{*}$ \\
\hline number $\times$ ant & 1,26 & 1.47 & $<1$ \\
\hline transitivity $\times$ lat & 1,26 & $7.27^{*}$ & $12.84 * *$ \\
\hline grammaticality $\times$ lat & 1,26 & $4.7^{*}$ & 1.11 \\
\hline number $\times$ lat & 1,26 & $<1$ & $<1$ \\
\hline transitivity $\times$ grammaticality $\times$ number & 1,26 & $3.59^{\wedge}$ & $4.13^{\wedge}$ \\
\hline transitivity $\times$ grammaticality $\times$ ant & 1,26 & $<1$ & 1.22 \\
\hline transitivity $\times$ number $\times$ ant & 1,26 & 2.84 & $3.82^{\wedge}$ \\
\hline grammaticality $\times$ number $\times$ ant & 1,26 & $4.03^{\wedge}$ & $3.01^{\wedge}$ \\
\hline transitivity $\times$ grammaticality $\times$ lat & 1,26 & $<1$ & $6.72 *$ \\
\hline transitivity $\times$ number $\times$ lat & 1,26 & $<1$ & $<1$ \\
\hline grammaticality $\times$ number $\times$ lat & 1,26 & $<1$ & 1.22 \\
\hline transitivity $\times$ ant $\times$ lat & 1,26 & $9.73^{* *}$ & $9.1 * *$ \\
\hline grammaticality $\times$ ant $\times$ lat & 1,26 & 2.12 & 2.6 \\
\hline number $\times$ ant $\times$ lat & 1,26 & $<1$ & 2.35 \\
\hline transitivity $\times$ grammaticality $\times$ number $\times$ ant & 1,26 & $<1$ & $<1$ \\
\hline transitivity $\times$ grammaticality $\times$ number $\times$ lat & 1,26 & 1.86 & 2.21 \\
\hline transitivity $\times$ grammaticality $\times$ ant $\times$ lat & 1,26 & $<1$ & $<1$ \\
\hline transitivity $\times$ number $\times$ ant $\times$ lat & 1,26 & $3.23^{\wedge}$ & 2.21 \\
\hline grammaticality $\times$ number $\times$ ant $\times$ lat & 1,26 & $<1$ & $<1$ \\
\hline transitivity $\times$ grammaticality $\times$ number $\times$ ant $\times$ lat & 1,26 & $<1$ & $<1$ \\
\hline
\end{tabular}

Topographic factors: ant $=$ anteriority; lat $=$ laterality.

$* * p<.01$

$* p<.05$

$\wedge .05<p<.1$ 